Georgia State University

ScholarWorks @ Georgia State University

\title{
The impact of Acceptance and Commitment Therapy versus education on stigma toward people with psychological disorders
}

\author{
Akihiko Masuda \\ Georgia State University, amasuda@gsu.edu \\ S. C. Hayes \\ University of Nevada - Reno, hayes@unr.edu \\ Lindsay B. Fletcher \\ lindsaybfletcher@gmail.com \\ P. J. Seignourel \\ K. Bunting
}

See next page for additional authors

Follow this and additional works at: https://scholarworks.gsu.edu/psych_facpub

Part of the Psychology Commons

\section{Recommended Citation \\ Masuda, Akihiko; Hayes, S. C.; Fletcher, Lindsay B.; Seignourel, P. J.; Bunting, K.; Herbst, S. A.; Twohig, M. P.; and Lillis, J., "The impact of Acceptance and Commitment Therapy versus education on stigma toward people with psychological disorders" (2007). Psychology Faculty Publications. 98. \\ https://scholarworks.gsu.edu/psych_facpub/98}

This Article is brought to you for free and open access by the Department of Psychology at ScholarWorks @ Georgia State University. It has been accepted for inclusion in Psychology Faculty Publications by an authorized administrator of ScholarWorks @ Georgia State University. For more information, please contact scholarworks@gsu.edu. 


\section{Authors}

Akihiko Masuda, S. C. Hayes, Lindsay B. Fletcher, P. J. Seignourel, K. Bunting, S. A. Herbst, M. P. Twohig, and J. Lillis 
Running head: ACT, EDUCATION, AND STIGMA

The Impact of Acceptance and Commitment Therapy versus Education on Stigma toward People with Psychological Disorders

Akihiko Masuda $^{\mathrm{a}, *}$, Steven C. Hayes ${ }^{\mathrm{a}}$, Lindsay B. Fletcher, ${ }^{\mathrm{a}}$ Paul J. Seignourel ${ }^{\mathrm{b}}$, Kara Bunting ${ }^{\mathrm{a}}$, Scott A. Herbst ${ }^{a}$, Michael P. Twohig ${ }^{a}$, \& Jason Lillis ${ }^{a}$

${ }^{\text {a }}$ Department of Psychology, University of Nevada, Reno, Reno, NV 89557-0062 USA

${ }^{\mathrm{b}}$ Department of Psychology, University of Florida, Gainesville, FL 32611-2250 USA

*Corresponding author at: Department of Family and Community Medicine, University of

Texas-Health Science Center at Houston, Houston, TX 77030, USA.

Tel.: +1 (713) 500-7549;

Fax: +1 (713) 500-7598.

Email Address: Akihiko.Masuda@uth.tmc.edu

Data analyzed for the present study were part of Aki Masuda's doctoral dissertation project at the University of Nevada, Reno.

A copy of the complete treatment manual is available from the first author, Aki Masuda. Aki Masuda is now an assistant professor at Georgia State University. Mike Twohig is now an assistant professor at Utah State University. 


\begin{abstract}
Acceptance and Commitment Therapy (ACT) has previously been shown to alter stigmatizing attitudes and to be relatively useful for psychologically inflexible participants. The present study is the first to bring those two findings together by comparing ACT to an education intervention for reducing stigma toward people with psychological disorders, and examining whether results differ for psychologically inflexible versus flexible individuals. A sample of college students $(\mathrm{N}=95)$ was randomly assigned to a $2 \frac{1}{2}$ hour ACT or educational workshop. Measures were taken before and after the workshop and at a one-month follow-up. ACT reduced mental health stigma significantly regardless of participants’ pre-treatment levels of psychological flexibility, but education reduced stigma only among participants who were relatively flexible and non-avoidant to begin with. Acceptance could be an important avenue of exploration for stigma researchers.
\end{abstract}

KEYWORDS: Acceptance; mindfulness; psychological flexibility; experimental avoidance; Acceptance and Commitment Therapy; education; prejudice; stigma; stigma toward people with psychological disorders. 
The Impact of Acceptance and Commitment Therapy versus Education on Stigma toward People with Psychological Disorders

People have more stigmatizing attitudes toward individuals with psychological disorders than those who suffer from physical diseases, particularly if they receive professional psychological services (e.g., Ben-Porath, 2002). Mental health stigma is associated with treatment underutilization (Kushner \& Sher, 1991), delay (Starr, Campbell, \&and Herrick, 2002), and premature termination (Sirey , Bruce, Alexopoulos, Perokic, Raue, Friedman et al., 2001), in addition to other consequences (e.g., Corrigan \& Penn, 1999) among stigmatized individuals with psychological disorders.

There are currently three common categories of interventions for stigma reduction: verbal confrontation of negative attitudes, education, and contact with stigmatized individuals along with education (Corrigan \& Penn, 1999). Among those, education and contact-based education programs have shown favorable results (e.g., Corrigan et al., 2001; Corrigan et al., 2002), but effects can be small and temporary (Corrigan, 2004). Furthermore, mechanisms of change are yet unclear (Penn \& Corrigan, 2002). Given the limited range of methods and results, there is clearly a need for additional intervention methods in this area.

Stigmatizing thoughts can be both rigid (Kurzban \& Leavy, 2001) and cognitively selfprotective (Haghighat, 2001), facilitating the stigmatizer to avoid perceived danger (Goffman, 1963). Contact-based education may be useful because it helps participants undermine beliefs that there is a real potential danger in the stigmatized, but it may leave relatively untouched other difficult thoughts and feelings (e.g., anxiety, thoughts about "us vs. them”) occasioned by stigmatized groups that can themselves be perceived as experiences that need to be avoided 
(Hayes, Bissett et al., 2004; Hayes, Luoma, Bond, Masuda, \& Lillis, 2006; Hayes, Wilson, Gifford, Follette, \& Strosahl, 1996).

This line of thinking suggests that psychological methods designed to undermine avoidance of difficult thoughts and feelings may be helpful in reducing the impact of stigma (Hayes, Niccolls, Masuda, \& Rye, 2002; cf., Corrigan \& Watson, 2002), and perhaps particularly so for those who are generally avoidant and psychologically inflexible. This idea comports with the empathy training literature, which suggests that one of the fundamental ways to increase a person's empathy toward others is to increase his or her own self-acceptance (e.g., Barnett, Thompson, \& Pfeifer, 1985; Kohut, 1984; Sweet \& Johnson, 1990). Mindfulness methods that enhance nonjudgmental and present-focused experience of self and others appear to be particularly relevant to that goal (e.g., Sweet \& Johnson, 1990).

Acceptance and Commitment Therapy (ACT; Hayes, Strosahl, \& Wilson, 1999) is well suited to test the value of this line of reasoning. ACT is a contextual behavioral intervention model derived from a contemporary behavior analytic perspective on language and cognition (Hayes, Barnes-Holmes, \& Roche, 2001) that uses acceptance, mindfulness, and values-directed behavior change strategies in order to increase psychological flexibility. ACT has been shown to influence the psychological impact of negative thoughts and feelings as well as problematic avoidance patterns in a wide range of psychological issues (Hayes et al, 2006), including stigma.

In one recent study, a workshop format of ACT appropriate for non-therapy interventions (“Acceptance and Commitment Training”; Hayes, Bissett, et al., 2004) was applied to the stigmatizing attitudes of licensed substance abuse counselors toward their clients. In this study, 90 alcohol and drug abuse counselors were randomly assigned to one-day workshops in either to ACT, multicultural training, or education in a biological model of substance abuse. As compared 
to the biological education condition, multicultural training reduced stigmatizing attitudes at post-intervention. However, these effects were not maintained at a 3-month follow-up. ACT reduced stigma at follow-up and with it workplace burnout. The impact of ACT was mediated by post-intervention changes in the believability of stigmatizing attitudes.

A second study compared ACT and education on racial and ethnic attitudes in a college classroom-based crossover design (Lillis \& Hayes, in press). ACT significantly increased ACT processes and pro-diversity action intentions as compared to education alone.

There is some evidence that the comparative effectiveness of ACT is particularly strong for psychologically inflexible individuals: those who show high levels of experiential avoidance, cognitive fusion, and inaction in the face of difficult thoughts and feelings (e.g., Zettle, 2003). Such inflexibility and avoidance (Wilson \& Murrell, 2004) appears to be a significant source of a wide range of psychological problems (Hayes et al., 2006; Kashdan, Barrios, Forsyth, \& Steger, 2006). However, no research has yet assessed whether ACT will have a comparatively greater impact on stigma in avoidant and inflexible individuals as compared to existing methods. That is the primary purpose of the present study, which tested an extremely short form of ACT (2 $1 / 2$ hours long) with college students as the target population. College students have been used in most previous studies on mental health stigma, which enable comparisons to previous studies (e.g., Corrigan et al., 2001; Penn \& Corrigan, 2002). Additionally, this population provides a ready sample of flexible and inflexible individuals.

\section{Method}

\section{Participants and Setting}

Participants were undergraduate college students who volunteered from psychology courses and completed informed consent. Participants received extra credit and \$10 
compensation for attendance.

Because this study was done in a group format, participants were recruited in 9 waves requiring at least 10 participants indicating they would come on a subject sign up sheet (thus, with an expected minimum group size after random assignment of 5). Fewer than 10 participants actually attended the workshop four times and in these occasions the type of intervention was randomly determined. All totaled 78 participants (82\%) were randomly assigned as individuals with the remaining 17 participants randomly assigned as a cohort.

Ninety-five participants (64 female, 2 participants failed to note their gender) attended the workshops; 52 (38 female. 2 unidentified) assigned to the ACT intervention and 43 (26 female) to the education intervention. The average age was 19.7 years. The majority of participants were non-Hispanic Caucasians (Non-Hispanic Caucasian=70, Asian/Pacific Islander=6, Hispanic=7, African American=2, multiethnic/others=8, and unidentified=2). Interventions

ACT and education conditions were delivered in a 150-minute workshop-format (total contact time of three hours, counting assessment). The ACT intervention was led by the fifth and sixth authors (KB, SH). They were graduate students who had been involved in numerous ACT trainings and workshops. The education intervention was led by the third author (LF), a graduate student, and an undergraduate research assistant. Although each intervention followed a very detailed manual, these co-facilitators received sufficient trainings (e.g.., co-facilitating a pilot workshop several times) prior to the present project.

Acceptance and Commitment Training (ACT). The protocol was largely drawn from the original ACT manual (Hayes, et al., 1999), with a modification of metaphors and exercises to target mental health stigma as the content. Emphasis was placed on the view that stigma is built 
into our normal use of language and the solution to these processes is more to be found in compassion and values than in automatic thoughts. Specific ACT exercises encouraged participants to notice how judgmental processes are automatic, prevalent, and related to mental health stigma. Prevalence data of psychiatric disorders (Kessler, McGonagle, Zhao, Nelson, Hughes, \& Eshleman, 1994) were used to normalize psychological struggles. The ubiquitous nature of psychological suffering was processed experientially along with the paradoxical effect of deliberate attempts to eliminate both self-stigma and stigmatizing attitudes toward people with psychological disorders (drawn from Hayes et al., 1999, pp. 124-125, and pp. 126-128). In order to increase the sense of understanding and empathy, participants were then asked to notice the parallel between their reactions to people with psychological disorders and their reactions to their own psychological struggles (e.g., self-stigma). The costs of self-stigmatization (e.g., sense of isolation, distress and entanglement from deliberate attempts to eliminate psychological struggles) were also experientially processed and acceptance and nonjudgmental skills for stigma toward self and others were trained (similar to Hayes et al., 1999, pp. 154-156, and pp. 192-196). Finally, participants were guided through the nature and importance of values and behavioral commitment to value-direction in the area of interpersonal relationships, and then went through a public values declaration exercise (functionally similar to Hayes et al., 1999, pp. 215-218).

Education .The education intervention consisted of a mixture of group activities, discussions, and didactic presentation designed to replace stigmatizing and biased thoughts with new informed ones. Given the possibility of paradoxical effects (Corrigan \& Penn, 1999), information was delivered in a non-confrontational manner. The condition covered the definition of stigma, diagnostic classifications of common psychological disorders and their prevalence (from Kessler, et al., 1994), and common stigmatizing attitudes toward people with 
psychological disorders (from Crisp et al., 2000). The social consequences of these attitudes (from Corrigan \& Penn, 1999; Link, 1987; Penn \& Martin, 1998: Perlick, Rosenheck, Clarkin, Sirey, Salahi, Struening, et al., 2001) were explored and less stigmatizing information was provided. Group members were encouraged to become more aware of their own attitudes toward psychological disorders and those suffering with them, and to use the information presented to be more accurate if their attitudes contained misconceptions.

Measures and Measurement Occasions

Participants were assessed at the beginning of workshop (pre), at the end of the workshop (post), and at a one-month follow-up. Participants filled out assessment packages across the three assessment periods at the intervention site.

The outcome measure was the Community Attitudes toward the Mentally Ill scale (CAMI; 40 items; Taylor \& Dear, 1981). The CAMI is a 5-point Likert, self-report questionnaire designed to measure attitudes toward the mentally ill and has adequate to good reliabilities (alpha of .68 to .88; Taylor \& Dear, 1981). The CAMI asks participants to rate their degree of agreement with each statement, ranging from 1 (strongly disagree) to 5 (strongly agree). Items were modified slightly to make the CAMI fit college student populations and their experiences: “mental illness” was replaced with "psychological disorder”; gender specific references (e.g., “a man”) with "a person”; “the mentally ill” became "a person with a psychological disorder" and “mental disturbance” was replaced with "psychological disturbance.” The CAMI has four subscales: (a) Authoritarianism, (b) Benevolence, (c) Social Restrictiveness, and (d) Community Approach. To reach an overall score Benevolence and Community Approach were subtracted from Authoritarianism and Social Restrictiveness, as has been done in other studies (e.g., Hayes 
et al., 2004). Possible scores range from -80 to 80, with higher scores indicating more stigmatizing attitudes.

The Acceptance and Action Questionnaire (AAQ; Bond \& Bunce, 2003; Hayes, Strosahl, Wilson, Bissett, Pistorello, Toarmino, et al., 2004) was used to categorize participants by their degree of psychological inflexibility, cognitive fusion, and experiential avoidance (in this study, we will use the term "psychological inflexibility” to refer to these ACT processes). The AAQ is a seven-point Likert scale with adequate reliability (alpha of .72 to .79; Bond \& Bunce, 2003; Hayes et al., 2004), and inquires about avoidance of emotions, fusion with thoughts, and the inability to act in the presence of difficult thoughts and feelings. The 16 item version (Bond \& Bunce, 2003) was used and scored so that higher scores correspond to higher levels of psychological flexibility.

In order to categorize participants, the mean score for clinical populations (Hayes, Strosahl, et al., 2004) was used as a cutoff. If a participant's pretreatment AAQ score was 66 or lower, the participant was categorized as being psychologically inflexible; if the score was 67 or higher, the participant was categorized as psychologically flexible.

Results

\section{Characteristics of Sample}

Of the 95 participants, 4 failed to complete post assessments; and 6 more failed to complete follow up assessments; thus $89 \%$ of the sample had complete data and were analyzed, 47 in ACT (14 were psychological inflexible or 30\%) and 38 in Education (10 were psychological inflexible, or $26 \%)$. Effects on Stigma 
Means and standard deviations of CAMI total scores for both groups are presented in Table 1. The results for the CAMI were analyzed using a 2 (Condition: ACT vs. education) by 2 (Psychological flexibility: flexible vs. inflexible) by 3 (Time: pre-treatment, post-treatment, follow-up) repeated measures ANOVA. The analysis showed a main effect for psychological flexibility, $F(1,81)=4.72, p<.05$, indicating that overall, inflexible participants were more stigmatizing than psychologically flexible participants. There was also a significant effect for time, $F(2,80)=20.26, p<.001$. Pairwise comparisons revealed a significant reduction of stigmatizing attitudes at post-treatment as compared to pre-treatment, $t(84)=7.42, p<.001$. While the gains deteriorated between post-treatment and follow-up, $t(84)=-2.89, p<.01$, stigmatizing attitudes were still reduced at follow-up as compared to pre-treatment, $t(84)=4.87$, $p<.001$.

The key question was addressed by the three way interaction between condition, psychological flexibility, and time. This interaction was significant, $F(1,81)=4.51, p<.05$. These results are shown in Figure 1. The interaction was decomposed both by looking at the effects of condition and psychological flexibility at each time point and by looking at treatment effects across time in each condition by psychological flexibility group. At pre-treatment, there were no effects of psychological flexibility, condition, or their interaction. At post-treatment, there was a main effect for psychological flexibility, $F(1,81)=5.38, p<.05$, with psychologically inflexible participants showing more stigmatizing attitudes than more flexible participants. There was no effect of condition, $F(1,81)=1.36, p>.1$, but there was a trend towards an interaction between condition and psychological flexibility, $F(1,81)=3.17, p=.08$. In the ACT condition, results did not differ by flexibility, $t(45)=0.40, p>.1$, but in the 
education condition, psychologically inflexible participants showed greater stigmatization than flexible participants, $t(36)=2.87, p<.01$.

The pattern at follow-up was similar. There was a main effect of psychological flexibility, $F(1,81)=4.10, p<.05$, with psychologically inflexible participants showing greater stigmatization, and a group by condition interaction, $F(1,81)=4.02, p<.05$. Once again, the results did not differ in the ACT condition by level of psychological flexibility, $t(45)=0.02, p>$ .1, but inflexible participants in the education condition showed higher levels of stigmatization, $t(36)=2.62, p<.05$.

Treatment effects in each of the four conditions by psychological flexibility groups were also examined. Figure 1 shows the results clearly. CAMI scores were significantly lower for all subgroups at post-treatment and follow-up as compared to pre-treatment, $F^{\prime}$ s $\geq 7, p$ 's $<.01$, except for psychologically inflexible participants exposed to education, who did not improve, $F(2,18)=0.08, p>.1$

\section{Discussion}

The present study revealed that a very short ACT or educational workshop could produce significant reductions in stigma toward people suffering from psychological problems, and significant gains were maintained after a month. The results varied, however, depending on the psychological characteristics of the participants. If participants avoided emotions, were fused with thoughts, and could not take valued action in the presence of difficult thoughts and feelings, education about people with psychological disorders and the stigma they face had no benefit. In contrast, the ACT intervention reduced stigmatizing attitudes regardless of the degree of inflexibility participants showed. 
This pattern of results suggests that some forms of stigma may reflect uninformed attitudes about legal, cultural, and institutional practices related to mental illness. In more experientially avoidant individuals, however, stigmatizing views may become entangled in psychologically avoidant processes linked to the perceived threats of the stigmatized condition (Goffman, 1963) and to the inability to deal with the thoughts and feelings that arise as a result. These differences might help explain the somewhat inconsistent results for education in the stigma literature (Corrigan \& Penn, 1999; Penn \& Corrigan, 2002). In some studies, those who have received more accurate information are more likely to improve attitudes toward persons with mental illness (e.g., Penn, Guynan, Daily, Spaulding, Garbin, \& Sullivan, 1994), but in others education has had no effect (e.g., Thornton \& Wahl, 1996). Similar inconsistencies have been reported for education about racial stereotypes (e.g., Devine, 1995; Pruegger \& Rogers, 1994). This variation has been argued to be related to the duration of education or types of information provided (Holms, Corrigan, Williams, Canar, \& Kubiak, 1999; Penn et al., 1994) but the dramatically different outcomes for education depending on participants' level of psychological flexibility raises the possibility that samples in previous research varied on this dimension, unbeknown to the investigators.

Given the importance of diversity training and other forms of stigma reduction in school, workplaces, and other institutions, one possible way to make use of the present findings would be to find way to integrate ACT methods into broadly disseminated diversity education. Although early effectiveness trials with ACT used well-trained therapists (Strosahl, Hayes, Bergin, \& Romano, 1998), more recent studies show that even minimally trained ACT therapists can produce large effects (Lappalainen et al., in press; Forman et al., in press), suggesting that dissemination to teachers or human resource professionals may be practically possible. The 
effort to create more widely disseminated ACT classes or workshops might be spurred on by evidence that they reduce anxiety and depression when used in health classes in schools (Livheim, 2004), decrease therapists’ burnout (Hayes et al., 2004), and increase the ability to learn new, empirically-supported methods when used in the workplace (Varra, 2006).

The present research has several methodological weaknesses. The sample is not large, particularly for those with low psychological flexibility. It is unclear which components might have been effective in these packages. Adherence to the closely scripted interventions was not formally assessed. Actual knowledge about psychological disorders was not assessed so we cannot be sure if the factor targeted by education actually changed. Measures that could capture other possible effects of acceptance-based interventions, such as empathy, were not used. Stigma measures included modified terms that may not be equivalent with the original scales. Cutoff AAQ scores used to dichotomize participants in terms of psychological inflexibility were derived form clinical populations, not from college populations.

Another problem is that the present research project exclusively relied on self-report measures. Stigma is often conceptualized as a multidimensional process (e.g., Kurzban \& Leavy, 2001) that evokes particular negative behavior, such as excessive avoidance. The CAMI only assesses the cognitive aspects of stigma, not its overt behavioral aspects. Behavioral measurement is difficult in this area, but the presence of now several studies on ACT and prejudice or stigma (Hayes et al., 2004; Lillis \& Hayes, in press; Varra, 2006) would seem to warrant the effort. A follow-up period that is longer than one month would be necessary to explore the long-term impact of the present interventions.

A final limitation is a possible avenue of exploration. The education condition included information regarding the ubiquitous nature of psychological struggles. This does not seem to be 
regularly included in educational interventions, and it seemed to spontaneously lead to group sharing and self-disclosure. This in turn may have reduced self-stigma in a way similar to the ACT condition. The relatively strong effect of education in this study could suggest that educational methods might usefully begin to promote acceptance, mindfulness, or empathy.

Despite these limitations, the present study provides new insights for stigma reduction research and practice. From an ACT perspective, the core of stigma is the objectification and dehumanization of people due to entanglement with verbal evaluations (Hayes, et al., 2002). Instead of directly challenging the content of stigma, ACT attempts to undermine the psychological impact of stigma by increasing a person’s acceptance, mindfulness, and perspective-taking repertoire, such as empathy toward self and others. By increasing the perceived sense of shared psychological experiences with the stigmatized (e.g., inevitability of psychological struggles in life), ACT attempts to undermine the impact of perceived sense of us vs. them, a major characteristic of stigmatization (e.g., Link \& Phelan, 2000; Crisp, et al., 2000). Acceptance and mindfulness interventions provide a new frontier for the alleviation of stigma, prejudice, and self-stigma. These are costly and difficult problems with broad impact on individuals and on society itself. The present findings buoy up an acceptance and mindfulness-based analysis (Hayes et al., 2002) of elements that maintain stigmatizing processes more generally. The cognitive and behavioral therapies have generally not been looked to as resources for the amelioration of these problems. However, the present study provides support for their relevance. 


\section{References}

Barnett, M. A., Thompson, M. A., \& Pfeifer, J. R. (1985). Perceived competence to help and the arousal of empathy. Journal of Social Psychology, 125, 679-680.

Ben-Porath, D. D. (2002). Stigmatization of individuals who receive psychotherapy: An interaction between help-seeking behavior and the presence of depression. Journal of Social and Clinical Psychology, 21, 400-413.

Bond, F. W., \& Bunce, D. (2003). The role of acceptance and job control in mental health, job satisfaction, and work performance. Journal of Applied Psychology, 88, 1057-1067.

Corrigan, P. W. (2004). Target-specific stigma change: A strategy for impacting mental illness stigma. Psychiatric Rehabilitation Journal, 28, 113-121.

Corrigan, P. W., \& Penn, D. L. (1999). Lessons from social psychology on discrediting psychiatric stigma. American Psychologists, 54, 765-776.

Corrigan, P. W., River, L. P., Lundin, R. K., Penn, D. L., Uphoff-Wasowski, K. Campion, J., et al., (2001). Three strategies for changing attributions about severe mental illness. Schizophrenia Bulletin, 27, 187-195.

Corrigan, P. W., Rowan, D., Green, A., Lindin, R., River, P, Uphoff-Wasowiski, K., et al. (2002). Challenging two mental illness stigmas: Personal responsibility and dangerousness. Schizophrenia Bulletin, 28, 293-309.

Corrigan, P. W., \& Watson, A. C. (2002). The paradox of self-stigma and mental illness. Clinical Psychology: Science and Practice, 9, 35-53.

Crisp, A. H., Gelder, M. G., Rix, S., Meltzer, H. I., \& Rowlands, O. J. (2000). Stigmatisation of people with mental illnesses. British Journal of Psychiatry, 177, 4-7. 
Devine, P. G. (1995). Prejudice and out-group perception. In A. Tesser (Ed.), Advanced social psychology (pp. 467-524). New York: McGraw-Hill.

Forman, E. M., Herbert, J. D., Moitra, E., Yeomans, P. D. \& Geller, P. A. (in press). A randomized controlled effectiveness trial of Acceptance and Commitment Therapy and Cognitive Therapy for anxiety and depression. Behavior Modification.

Goffman, E. (1963). Stigma: Notes on the management of spoiled identity. New York: Simon \& Schuster.

Haghighat, R. (2001). A unitary theory of stigmatization: Pursuit of self-interest and routes to destigmatisation. British Journal of Psychiatry, 178, 207-215.

Hayes, S. C., Barnes-Holmes, D., \& Roche, B. (Eds.). (2001). Relational Frame Theory: A PostSkinnerian account of human language and cognition. New York: Plenum Press.

Hayes. S. C., Bissett, R., Roget, N., Padilla, M., Kohlenberg, B. S., Fisher, G., et al. (2004). The impact of Acceptance and Commitment Training and Multicultural Training on the stigmatizing attitudes and professional burnout of substance abuse counselors. Behavior Therapy, 35, 821-835.

Hayes, S. C., Luoma, J., Bond, F., Masuda, A., and Lillis, J. (2006). Acceptance and Commitment Therapy: Model, processes, and outcomes. Behaviour Research and Therapy, 44, 1-25.

Hayes, S. C., Niccolls, R., Masuda, A., \& Rye, A. K. (2002). Prejudice, terrorism, and behavior therapy. Cognitive and Behavioral Practice, 9, 296-301.

Hayes, S. C. Strosahl, K. D., \& Wilson, K. G. (1999). Acceptance and Commitment Therapy: An experiential approach to behavior change. New York: Guilford Press. 
Hayes, S. C., Strosahl, K. D., Wilson, K. G., Bissett, R. T., Pistorello, J., Toarmino, D., et al. (2004). Measuring experiential avoidance: A preliminary test of a working model. The Psychological Record, 54, 553-578.

Hayes, S. C., Wilson, K. G., Gifford, E. V., Follette, V. M., \& Strosahl, K. (1996). Experiential avoidance and behavioral disorders: A functional dimensional approach to diagnosis and treatment. Journal of Consulting and Clinical Psychology, 64, 1152-1168.

Holmes, E. P., Corrigan, P. W., Williams, P., Canar, J., \& Kubiak, M. A. (1999). Changing attitudes about schizophrenia. Schizophrenia Bulletin,25, 447-456.

Kashdan, T. B., Barrios, V., Forsyth, J. P., \& Steger, M. F. (2006). Experiential avoidance as a generalized psychological vulnerability: Comparisons with coping and emotional dysregulation strategies. Behaviour Research and Therapy, 44, 1301-1320.

Kessler, R. C., McGonagle, K. A., Zhao, S., Nelson, C. B., Hughes, M., \& Eshleman, S. (1994). Lifetime and 12-month prevalence of DSM-III-R psychiatric disorders in the United States: Results from the National Comorbidity Survey. Archives of General Psychiatry, 51, 8-19.

Kohut, H. (1984). How does analysis cure? Chicago: University of Chicago Press.

Kurzban, R., \& Leary, M R. (2001). Evolutionary origins of stigmatization: The functions of social exclusion. Psychological Bulletin, 127, 187-208.

Kushner, M. G., \& Sher, K. J. (1991). The relation of treatment fearfulness and psychological service utilization: An overview. Professional Psychology: Research and Practice, 22, 196-203. 
Lappalainen, R., Lehtonen, T., Skarp, E., Taubert, E., Ojanen, M., \& Hayes, S. C. (in press). The impact of CBT and ACT models using psychology trainee therapists: A preliminary controlled effectiveness trial. Behavior Modification.

Lillis, J. \& Hayes, S. C. (in press). Applying acceptance, mindfulness, and values to the reduction of prejudice: A pilot study. Behavior Modification.

Link, B. G. (1987). Understanding labeling effects in the area of mental disorders: An assessment of the effects of expectations of rejection. American Sociological Review, 52, 96-112.

Link, B. G., \& Phelan, J. C. (2001). Conceptualizing stigma. Annual Review of Sociology, 27, 363-385.

Livheim, F. (2004). Acceptance and Commitment Therapy i skolan - att hantera stress. En randomiserad, kontrollerad studie. Unpublished thesis. University of Uppsala, Sweden.

Penn, D. L., \& Corrigan, P. W. (2002). The effects of stereotype suppression on psychiatric stigma. Schizophrenia Research, 55, 269-276.

Penn, D. L., Guynan, K., Daily, T., Spaulding, W. D., Garbin, C. P., \& Sullivan, M. (1994). Dispelling the stigma of schizophrenia: What sort of information is best? Schizophrenia Bulletin, 20, 567-577.

Penn, D. L., \& Martin, J. (1998). The stigma of severe mental illness: Some potential solutions for a recalcitrant problem. Psychiatric Quarterly. Special Issue: New frontiers in the psychiatric rehabilitation of schizophrenia, 69, 235-247.

Perlick, D. A., Rosenheck, R. A., Clarkin, J. F., Sirey, J. A., Salahi, J., Struening, E. L., et al. (2001) Adverse effects of perceived stigma on social adaptation of persons diagnosed with bipolar affective disorder. Psychiatric Services, 52, 1627-1632. 
Pruegger, V. J., \& Rogers, T. B. (1994). Cross-cultural sensitivity training: Methods and assessment. Journal of Intercultural Relations, 18, 369-387.

Sirey, J. A., Bruce, M. L., Alexopoulos, G. S., Perokic, D. A., Raue, P., Friedman, S. T., et al. (2001). Perceived Stigma as a predictor of treatment discontinuation in young and older outpatients with depression. The American Journal of Psychiatry, 158, 479-481.

Starr, S., Campbell, L. R., \& Herrick, C. A., (2002). Factors affecting use of the mental health system by rural children. Issues in Mental Health Nursing, 23, 291-304.

Strosahl, K. D., Hayes, S. C., Bergan, J., \& Romano, P. (1998). Does field based training in behavior therapy improve clinical effectiveness? Evidence from the Acceptance and Commitment Therapy training project. Behavior Therapy, 29, 35-64.

Sweet, M. J., \& Johnson, C. G. (1990). Enhancing empathy: The interpersonal implications of a Buddhist meditation technique. Psychotherapy, 27, 19-29.

Taylor, S. M., \& Dear, M. J. (1981). Social community attitudes toward the mentally ill. Schizophrenia Bulletin, 7, 225-240.

Thornton, J. A. \& Wahl, O. F. (1996). Impact of a newspaper article on attitudes toward mental illness. Journal of Community Psychology, 24, 17-25.

Varra, A. A. (2006). The effect of Acceptance and Commitment Training on clinician willingness to use empirically-supported pharmacotherapy for drug and alcohol abuse. Unpublished dissertation available from the University of Nevada, Reno.

Wilson, K. G., \& Murrell, A. R. (2004). Values work in Acceptance and Commitment Therapy: Setting a course of behavioral treatment. In S. C. Hayes, V. M. Follette, \& M. M. Linehan (Eds.), Mindfulness and acceptance: Expanding the cognitive-behavioral tradition (pp. 120-151). New York: Guilford. 
ACT, Education, and Stigma 20

Zettle, R. D. (2003). Acceptance and commitment therapy (ACT) vs. systematic desensitization in the treatment of mathematics anxiety. The Psychological Record, 53, 197-215. 
Table 1: CAMI Average Scores, Standard Deviations, and Effect Sizes by Condition and Experiential Avoidance and Time

$\begin{array}{lccc} & \text { Follow- } & \\ \text { Pre Post } & \text { Pre-Post } & \text { Up } & \end{array}$

\begin{tabular}{|c|c|c|c|c|c|}
\hline & & & Within $d$ & & Within $d$ \\
\hline \multicolumn{6}{|l|}{ ACT } \\
\hline Low Flexibility & -24.29 & -34.64 & & -32.36 & \\
\hline$(N=14)$ & & (12.83) & .91 & (12.79) & .71 \\
\hline High Flexibility & -28.64 & -36.42 & & -32.42 & \\
\hline$(N=33)$ & $(11.30)$ & (14.63) & .60 & (13.22) & .31 \\
\hline \multicolumn{6}{|l|}{ Education } \\
\hline Low Flexibility & -24.30 & -24.90 & & -23.80 & \\
\hline$(N=10)$ & (13.86) & (17.95) & .04 & $(14.79)$ & .03 \\
\hline High Flexibility & -29.54 & -38.46 & & -36.82 & \\
\hline$(N=28)$ & $(14.02)$ & $(10.61)$ & .72 & (13.00) & .54 \\
\hline \multicolumn{6}{|c|}{ Between Condition Cohen's $d$ : } \\
\hline & & & Diff score & & Diff score \\
\hline Low Flexibility & & .62 & .80 & .62 & .88 \\
\hline High Flexibility & & -.16 & -.13 & -.34 & -.37 \\
\hline
\end{tabular}

Note . CAMI = Community Attitudes toward the Mentally Ill; ACT = Acceptance and Commitment Training; Standard deviations are enclosed in parentheses. 
ACT, Education, and Stigma 22

\section{Figure Caption}

Figure 1. CAMI total scores at pre, post, and follow-up for ACT and Education conditions by high and low psychological flexibility groups. 


\section{Stigmatizing Attitudes Toward Persons with \\ Psychological Disorders}

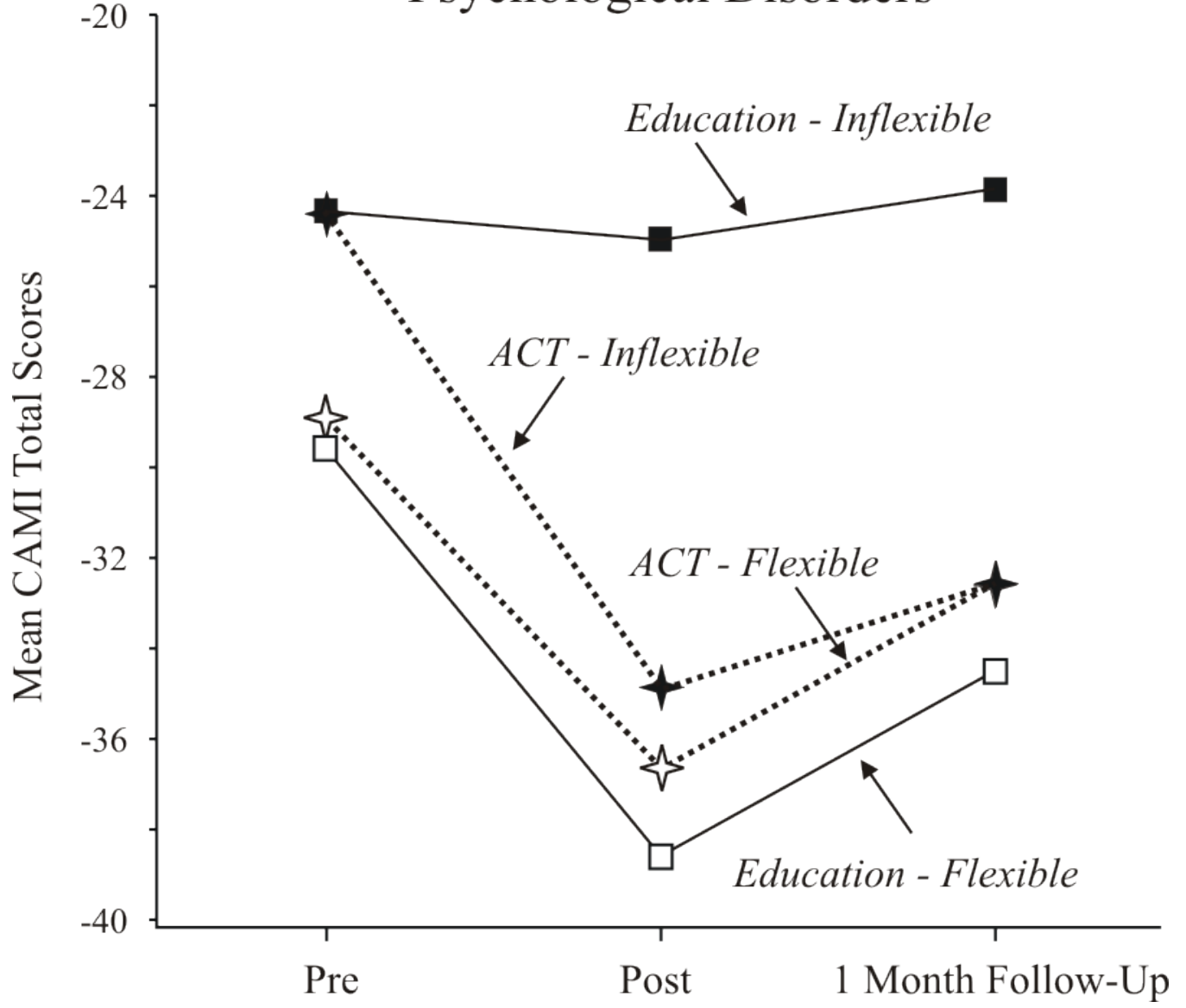

